\title{
Advantages of the Marlo anatomical socket (MAS) for transfemoral prosthesis
}

\author{
M.G. Gusev, G.A. Lein, S.V. Alzoba
}

The limited liability company Prosthetic and orthopedic center «Scoliologic.ru», St. Petersburg, Russian Federation

\begin{abstract}
Introduction Transfemoral socket designs commonly used with ischial tuberosity as the key weight-bearing part or accomodating the ischial tuberosity show some inefficiencies. The most recent advancement in socket design has provided transfemoral amputees with new options, however, it is not well known in Russia. Objective To explore theoretical and practical aspects of fabricating the Marlo anatomical socket (MAS) for transfemoral amputations and evaluate its application in clinical settings in Russia. Material and methods The new ischial containment socket design was shown to have advantages over conventional transfemoral sockets using comparative ichnographic studies. Results The MAS socket demonstrated improved cosmesis and appearance for the patient, increased sitting comfort, greater range of motion for the prosthetic limb and enhanced stability. Conclusion The technology requires no additional equipment and special fixturing. The new socket design can be successfully used by prosthetists in Russia to allow above knee amputees benefit from properly fitting socket. Keywords: transfemoral amputation, socket, prosthetic, lower limb
\end{abstract}

\section{INTRODUCTION}

The prosthetic socket is a critical element in a successful prosthesis. Even high-tech prosthetic components may fail to provide a reliable interface between the residual limb and the prosthetic socket. The socket is crucial for transfemoral amputees. The socket shape is determined by its proximal portion or the brim area and the design is based mainly on clinical experience of the prosthetist searching for ideas, using creative techniques to meet the demands of amputees.

There is a variety of transfemoral socket designs used in Russia. Transverse and oval shape is most common with the posterior wall supporting the ischial tuberosity (IT) and the gluteal muscles located on a socket brim. Longitudinal oval socket is less common with IT being inside of the brim and wrapped up by the socket wall [1, 2, 3, 4]. All the designs somehow provide support to IT in the proximal part of the socket to bear the weight $[5,6]$. International practice with transverse oval and longitudinal oval sockets indicated to shortcomings at the brim with limited range of motion in the amputee's hip joint and overloaded ischial ramus, as well as unacceptible cosmesis that resulted with posterior trim line being perceptible under the patient's clothing.

A new approach was modified by engineerprosthetist Marlo Ortiz based on long term clinical experience with hundreds of transfemoral amputees creating a more intimately fitting socket for patients $[7,8]$. The new above-knee socket design was called the Marlo Anatomical Socket (M.A.S.). The socket was incorporated into the Standards for Prosthetics and Orthotics in the U.S. and Europe, however, it is not a common use in Russia. We took an exclusive certified master course from the author Marlo Ortiz to learn theoretical and practical aspects of fabricating the MAS socket to use it in clinical practice.

\section{MATERIAL AND METHODS}

The creation of the MAS socket starts with osseous-ligamenteous stump measurements from the reference point at the ischial ramus: average angles vary between $25-30^{\circ}$ for males and 3035 degrees for females; determining medial and lateral anteroposterior dimensions; mediolateral and diagonal dimensions. Then a configuration of the socket brim is drawn on the plotting paper using the author's formula. A flexible wire is used to span the configuration to be applied for moulding the socket brim for the residual limb. Special coefficients are used for processing the inferior mold levels (Table 1).

Kinetic comparisons of geometrical structure of the stride of transfemoral amputee gait using conventional transverse oval socket $(n=30)$ and the MAS socket $(\mathrm{n}=30)$ were performed employing ichnography. Participants were requested to walk over a ichnographic walkway with open eyes (OE) and closed eyes (CE). Step length (SL), step width (SW), foot angle (FA), displacement of the gravity axis over the centerline and velocity of the gait were measured using a printed shape of a shoe footprint made with chalk pastels. 
Table 1

Approximate values of coefficients for processing the mold of the residual limb

\begin{tabular}{|c|c|c|c|c|c|c|c|c|c|c|c|c|}
\hline \multirow{3}{*}{$\begin{array}{l}\text { Level } \\
\text { below } \\
\text { ischium } \\
(\mathrm{cm})\end{array}$} & \multicolumn{12}{|c|}{ Stump length } \\
\hline & \multicolumn{3}{|c|}{$8-13 \mathrm{~cm}$} & \multicolumn{3}{|c|}{$15-18 \mathrm{~cm}$} & \multicolumn{3}{|c|}{$20-23 \mathrm{~cm}$} & \multicolumn{3}{|c|}{$25-40 \mathrm{~cm}$} \\
\hline & $\mathrm{SS}^{*}$ & SMD & SHD $* * *$ & $\mathrm{SS}^{*}$ & $\mathrm{SMD}^{* * *}$ & SHD & $S^{*}$ & SMD $* * *$ & SHD $* * * *$ & $S^{*}$ & $\mathrm{SMD}^{* * *}$ & SHD \\
\hline 2.5 & 2.9 & 2.5 & 2.1 & 2.9 & 2.5 & 2.1 & 2.5 & 2.1 & 1.8 & 2.1 & 1.8 & 1.5 \\
\hline 5 & 2.5 & 2.1 & 1.8 & 2.5 & 2.1 & 1.8 & 2.1 & 1.8 & 1.5 & 1.8 & 1.5 & 1.2 \\
\hline 7.5 & 2.1 & 1.8 & 1.5 & & & & & & & & & \\
\hline 10 & 1.8 & 1.5 & 1.2 & 1.5 & 1.2 & 0.9 & 1.5 & 1.2 & 0.9 & 1.5 & 1.2 & 0.9 \\
\hline 12.5 & 1.5 & 1.2 & 0.9 & & & & & & & & & \\
\hline 15 & & & & 1.2 & 0.9 & 0.6 & 0.9 & 0.6 & 0.6 & 0.9 & 0.9 & 0.6 \\
\hline 20 & & & & & & & 0.6 & 0.3 & 0.3 & 0.6 & 0.6 & 0.3 \\
\hline 25 & & & & & & & & & & 0.3 & 0.3 & 0.3 \\
\hline 30 & & & & & & & & & & 0.3 & 0.3 & 0.3 \\
\hline 35 & & & & & & & & & & 0 & 0 & 0 \\
\hline
\end{tabular}

RESULTS

The MAS socket is characterised by an extremely low posterior trim line to enable easier encapsulation of residular limb (Fig. 1, 2).

The posterior, medial and anterior walls of the socket are lowered as compared to conventional sockets. The posterior wall usually terminates at the level of the gluteal fold to allow the inferior line of the gluteus maximus muscle sit outside the socket. There is greater space for the gluteal muscle group avoiding the asymmetry at the prosthetic side in unilateral amputations. One additional benefit of the MAS design is the exceptional cosmesis that results in the trim lines being imperceptible under the patient's clothing. The inferior posterior trim line of the socket does not push the buttock to a higher level as compared to the intact side in unilateral amputations providing better gait pattern. The low profile MAS socket facilitates an added comfort for amputees because they can sit on their

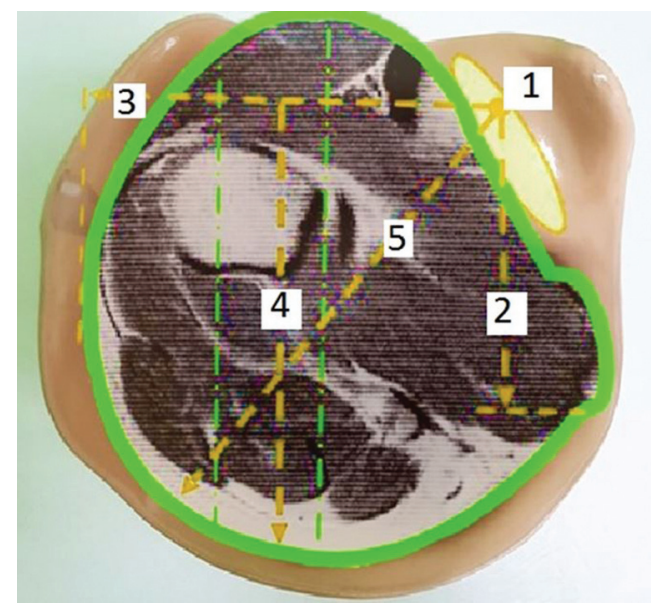

Fig. 1 Appearance of the socket and major measurements at the brim level: 1 - reference point; 2 - medial anteroposterior dimensions; 3 - mediolateral dimensions; 4 - lateral anteroposterior dimensions; 5, diagonal dimension gluteal muscle group rather than on a hard socket brim. Amputees also comment on the added comfort because they sit on their gluteal muscle group, rather than on a hard socket brim of conventional ischial containment designs preventing any sitting discomfort and pelvic imbalance. The more posterior containment design of socket means that the ischium easily exits the socket.

The medial wall is generally lowered to avoid pressure on the inguinal-perineal fold and the inferior portion of pelvis preventing entry of the ischial tuberosity into the socket. An additional benefit with the MADS design includes the loading exerted neither on bone structures nor on the ischio-pubic-ramus and the ischial tuberosity. A special pelotte is used to put pressure on the femoral adductor muscle to contain the ischio-pubic-ramus over the medial aspect of the socket brim to ensure mediolateral stability of the stump in the socket.

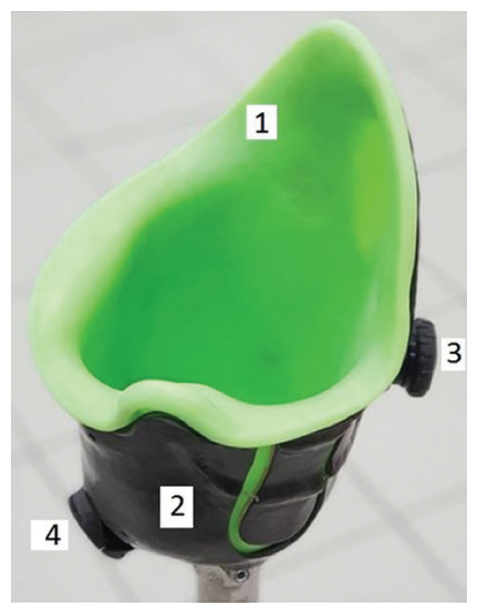

Fig. 2 Appearance of the fabricated MAS socket for transfemoral amputations: 1 - HTV inner socket; 2 - outer socket; 3 - Revofit adjustable socket system; 4 - vacuum forming adaptor 
The MAS socket has apparent clinical benefits for geriatric amputees because nerves and vessels are not squeezed by the prominence of the anterior pelotte of the transverse oval socket with an available enlargement pocket in the design. The location and the contours of the enlargement play a crucial role for the functionality of the socket. The pocket can be recommended for obliterating vascular diseases of lower limbs and diabetes mellitus. Full contact weightbearing is distributed through the MAS socket with the basic control muscles being located at special pockets and the bottom side of the residual limb to be provided with muscle 'cushions' to accommodate hydrostatic integration of the residual limb into the socket.

The MAS socket permits a full range of active and passive hip motion and there is almost no limitation in the range of motion of the hip, flexion, extension, abduction, and adduction of the stump and the prosthetic extremity. This freedom allows the patient to sit cross-legged and maximally abduct the leg. The lowered socket brim allows the amputee to take off the prosthesis with ease and greater confidence as compared to conventional constructs that is important for elderly users. The MAS design consists of an inner socket in combinations with outer socket. Membrane or vacuum silicone covers are used for flexible transfemoral soft-walled inner sockets as well as customised sockets made of supra soft polymer.

We introduced some improvements in MAS socket applications to reduce costs of the socket and enhance its functionality. High temperature vulcanized (HTV) silicone rubber was used to make customised inner

socket with optimal elasticity to ensure full contact between the socket and the residual limb and the use of skeletisation elements in the outer socket. A droplike window was made on the lateral aspect of the outer socket for more comfortable loading of the greater trochanter covered by external hard pelotte. A profiled tongue was cut at the posterior aspect of the outer socket for substantial volume fluctuations and was connected with a hinge on the Revofit, adapted from the dial-string tightening system on modern ski boots. This was practical for primary prosthetic users and patients with vascular impairment of lower limbs.

Kinetic comparisons of geometrical structure of the stride of transfemoral amputee gait using conventional transverse oval socket $(n=30)$ and the MAS socket $(n=30)$ employing ichnography are presented in Table 2.

SL was shown to decrease by $18 \%$, and SW increase by $30 \%$ of normal values in transfenoral amputees with classical socket. MAS socket users demonstrated less decrease $(10 \%)$ in SL and less increase in SW (10-15\% of normal values). FA showed nearly normal measurements and was not used as compensatory mechanism to improve dynamic stability and barycentering of the gait in the groups. Gait velocity at several walkways measured $2.31 \pm 0.25 \mathrm{~km} / \mathrm{h}$ in conventional group and $27 \pm 0.25 \mathrm{~km} / \mathrm{h}$ in MAS amputees. Deviation of the progression line over the steering axis was inconsiderable (up to $12 \%$ ) with coronal migration over the longitudinal advance line being comparable to normal deviations (up to $9 \%$ ) with return in $90 \%$ of the cases.

Table 2

Main geometrical measurements of the prosthetic stride

\begin{tabular}{|l|c|c|c|c|c|c|c|c|}
\hline \multirow{2}{*}{} & \multicolumn{2}{|c|}{ SL $(\mathrm{cm})$} & \multicolumn{2}{c|}{ SW $(\mathrm{cm})$} & \multicolumn{2}{c|}{ FA (degrees) } & \multicolumn{2}{c|}{ Gravity axis } \\
\cline { 2 - 9 } & OE & CE & OE & CE & OE & CE & OE & CE \\
\hline Transverse oval socket & $31 \pm 0.5$ & $27 \pm 0.5$ & $10 \pm 0.5$ & $13 \pm 0.5$ & $6 \pm 0.5$ & $7 \pm 0.5$ & $0.42 \pm 0.2$ & $1.54 \pm 0.3$ \\
\hline MAS socket & $34 \pm 0.3$ & $30 \pm 0.3$ & $9 \pm 0.3$ & $12 \pm 0.3$ & $6 \pm 0.5$ & $7 \pm 0.5$ & $0.31 \pm 0.2$ & $1.38 \pm 0.3$ \\
\hline
\end{tabular}

\section{DISCUSSION}

Current socket design for transfemoral amputees include two types of sockets, the ischial containment (IC) sockets to enclose ischial tuberosity and the ischial ramus containment (IRC) prosthetic sockets to enclose the ischial ramus. J.Sabolich was the first to use the term "ischial containment" in print in 1985 [9]. Many variations were proposed within the IC philosophy by International Society for Prosthetics and Orthotics (ISPO) in 1999 and California State University Domingues Hills (CSUDH) in 2000. The design offered by Marlo Ortiz is based on the ischeal containment type socket with several variations. The ischial tuberosity and part of the ramus as well as the medial aspect of the ramus are encapsulated within the medial aspect of the socket brim. Japanese researchers of University of Occupational and Environmental Health (UOEH) [10] examined position of the femur in transfemoral amputees using the ischial-ramal containment (IRC) socket and quadrilateral (QL) socket with computed tomography. The stump of the IRC group was maintained significantly more adducted during one foot standing on the prosthesis than that in the QL group. The IRC patients reported a tender feeling of the stump and were more comfortable 
sitting, going up and down the stairs. M. Fairly [7] suggested that the MAS socket design was a revolution in the development of ischial containment socket concepts. There are several benefits of the new design over a conventional ischial containment socket design and the existing IRC sockets. The benefits include the location of the medial wall being parallel to the ischial ramus angle with the pelotte provided for the ischialramal containment as well as special channels for muscle groups: femoral flexors, extensors, adductors and a channel for the femur. The MAS socket design continued to arouse interest throughout orthotic and prosthetic community. M. Traballesi et al. [11] reported lower energy cost of walking and greater prosthesis-related perceived mobility in transfemoral amputees with the MAS than in those with IC socket using a portable gas analyzer and the prosthetic evaluation questionnaire. R. Klots et al. [12] reported functional improvements with the MAS socket design provoked during gait and during daily activities. The global amplitude in the hip was significantly higher for the MAS socket $\left(139.5^{\circ}\right)$ compared to the IC socket $\left(125.4^{\circ}\right)$. Clinical outcomes and spacial gait parameters seen in our series are in line with the reported functional findings. The IRC socket of MAS design has shown apparent clinical benefits and must be includred in the list of sockets used for transfemoral amputees in Russia. In addition to manual individual fabrication of the socket for transfemoral prosthesis including the MAS design that is a very labour intensive process and requires experienced and highly skilled practitioners, automated CAD/CAM technologies are in current clinical use as well. The fabrication techniques we employed included manual individual fabrication of the MAS socket that facilitated positive clinical and biomechanical results, and automated fabrication of the socket with CIDOP ortopedia (Mexico) and Rodin4D CAD/CAM software (France). Automated fabrication with CAD-CAD techniques, 2D-, 3Dscanners were not shown to be common in lower limb prosthesis at the Russian orthotic and prosthetic enterprises [13]. Further acquisition of the MAS socket can be produced with customised manual fabrication or with automated fabrication techniques at specialised CAD-CAM orthotic and prosthetic facilities. The institutions should aim at automated and simplified fabrication of the sockets and at database collection of socket modelling for transfemoral amputees to allow comparative medical research providing evidence about the effectiveness.

\section{CONCLUSION}

General prosthetics practice shows there is no single preferred socket design for transfemoral amputees and for specific clinical scenario. Patients can use different socket designs over the course of their rehabilitation and the demands can change over the lifetime. So clinicians and prosthetists must be able to choose a socket design from those available worldwide.

Theoretical knowledge of the MAS socket, practical use and clinical evaluation of the outcomes have shown that the socket design can be applied for patients of any age and is compatable with the concept of modular prosthetic systems. Ichnographic findings indicated to the benefits of MAS sockets with increased step length, step width and gait velocity as compared to the parameters measured for conventional sockets. However, fabrication of the socket design is a multistaged process that requires highly skilled practitioners and clinicians. Although the design is based on simple principles and different from other socket designs the fitting process is crucial to ensure the placement and contours to be appropriate to individual's limbs. CAD-CAM technologies available in Russia can be practical for the fabrication of the sockets. MAS sockets need further exploration in transfemoral amputees with the residual limb protruding under the skin or painful scars at the bottom edge of the stump due to high loading force transferred from the socket to all soft tissues including the bottom edge of the residual limb.

\section{REFERENCES}

1. Susliaev V.G., Shcherbina K.K., Sobolev S.E., Smirnova L.M., Kurdybailo S.F., composers. Slozhnoe i atipichnoe protezirovanie goleni i bedra: metod. posobie [Complex and atypical prosthetics of the leg and femur: a technique manual]. SPb., 2011, 120 p. (in Russian)

2. Dymochka M.A., Sukhoverkhova A.I., Spivak B.G., eds. Rukovodstvo po protezirovaniiu i ortezirovaniiu. V 2 ch. [Manual on Prosthetics and Orthotics. In 2 parts]. M.m., Poligraf-plius, 2016. (in Russian)

3. Susliaev V.G., Shcherbina K.K., Sobolev S.E., Kantemirova R.K., Kurdybailo S.F., Gerasimova G.V., Strukova N.V., Iankovskii V.M., Burnos A.A., composers. Podgotovka i lechebno-trenirovochnoe protezirovanie invalidov pozhilogo vozrasta s kultei goleni $i$ bedra: metod. rekomendatsii [Preparation and treatment-training prosthetics of elderly disabled persons with leg and femur stump: a technique manual]. SPb., 2017, 75 p. (in Russian) 
4. Susliaev V.G., Iankovskii V.M. Protezirovanie posle amputatsii nizhnikh konechnostei. Obshchie polozheniia [Prosthetics after amputation of the lower limbs. General conditions]. Ponomarenko G.N., ed. Reabilitatsiia Invalidov : nats. ruk. [Rehabilitation of the disabled: a national guide]. M., GEOTAR-Media, 2018, pp. 271-273. (in Russian)

5. Dillon M.P. Ischial containment socket designs: Insights into socket geometry and coronal plane alignment. Proceedings of the $12^{\text {th }}$ World Congress of the International Society for Prosthetics and Orthotics. Canada, Vancouver, 2007, p. 53.

6. Michael J.W. Coronal plane stability and alignment of transfemoral prosthetics sockets. Proceedings of the $12^{\text {th }}$ World Congress of the International Society for Prosthetics and Orthotics. Canada, Vancouver, 2007, p. 54.

7. Fairley M. M.A.S. socket: a transfemoral revolution. $O \& P$ Edge, 2004, vol. 3. Available at: http://www.oandp.com/ articles/2004-06_03.asp.

8. Trower T.A. Changes in lower extremity prosthetic practice. Phys. Med. Rehabil. Clin. N. Am., 2006, vol. 17, no. 1, pp. 23-30, v-vi. DOI: 10.1016/j.pmr.2005.10.003.

9. Sabolich J. Contoured adducted trochanteric-controlled alignment method (CAT-CAM): Introduction and basic principles. Clinical Prosthetics \& Orthotics, 1985, vol. 9, no. 4, pp. 15-26.

10.Hachisuka K., Umezu Y., Ogata H., Ohmine S., Shinkoda K., Arizono H. Subjective evaluations and objective measurements of the ischial-ramal containment prosthesis. J. UOEH, 1999, vol. 21, no. 2, pp. 107-118.

11.Traballesi M., Delussu A.S., Averna T., Pellegrini R., Paradisi F., Brunelli S. Energy cost of walking in transfemoral amputees: Comparison between Marlo Anatomical Socket and Ischial Containment Socket. Gait Posture, 2011, vol. 34, no. 2, pp. $270-274$. DOI: 10.1016/j.gaitpost.2011.05.012.

12.Klotz R., Colobert B., Botino M., Permentiers I. Influence of different types of sockets on the range of motion of the hip joint by the trans-femoral amputee. Ann. Phys. Rehabil. Med., 2011, vol. 54, no. 7, pp. 399-410. DOI: 10.1016/j.rehab.2011.08.001.

13.Shcherbina K.K., Susliaev V.G., Golubeva Iu.B., Sokurov A.V., Ermolenko T.V., Iankovskii V.M. Analiz deiatelnosti proteznoortopedicheskikh predpriiatii po protezirovaniiu i ortezirovaniiu nizhnikh konechnostei s vozmozhnostiu importozameshcheniia [Analyzing the activities of prosthetic-orthopedic enterprises for prosthetics and orthotics of the lower limbs with the possibility of import substitution]. Vestnik Rossiiskoi Voenno-meditsinskoi Akademii, 2018, no. 4 (64), pp. 131-137. (in Russian)

Received: 17.09.2019

\section{Information about the authors:}

1.Maxim G. Gusev, M.D., Ph.D., The limited liability company Prosthetic and orthopedic center «Scoliologic.ru», St. Petersburg, Russian Federation, Email: mgfxspb@gmail.com

2. Grigory A. Lein, M.D., Ph.D., The limited liability company Prosthetic and orthopedic center «Scoliologic.ru», St. Petersburg, Russian Federation, Email: lein@scoliologic.ru

3. Sergey V. Alzoba, M.D., The limited liability company Prosthetic and orthopedic center «Scoliologic.ru», St. Petersburg, Russian Federation, Email: priem@scoliologic.ru 